\title{
Effects of Oleate-rich and Linoleate-rich Diets on the Susceptibility of Low Density Lipoprotein to Oxidative Modification in Mildly Hypercholesterolemic Subjects
}

Peter Reaven, Sampath Parthasarathy, Barbara J. Grasse, Elizabeth Miller, Daniel Steinberg, and Joseph L. Witztum Division of Endocrinology and Metabolism, Department of Medicine, University of California, San Diego, La Jolla, California 92093

\begin{abstract}
We report the results of feeding oleate- or linoleate-enriched diets for 8 wk to mildly hypercholesterolemic subjects and the resulting alterations in composition and functional properties of their plasma LDL and HDL. LDL isolated from subjects on oleate-enriched diets was less susceptible to copper-mediated oxidation, as measured by conjugated diene and lipid peroxide formation, and less susceptible to LDL-protein modification, as evidenced by reduced LDL macrophage degradation after copper- or endothelial cell-induced oxidation. For all subjects, the percentage of 18:2 in LDL correlated strongly with the extent of conjugated diene formation $(r=0.89, P<0.01)$ and macrophage degradation ( $r=0.71, P<0.01)$. Oxidation of LDL led to initial rapid depletion of unsaturated fatty acids in phospholipids followed by extensive loss of unsaturated fatty acids in cholesteryl esters and triglycerides. Changes in HDL fatty acid composition also occurred. However, HDL from both dietary groups retained its ability to inhibit oxidative modification of LDL. This study demonstrates that alterations in dietary fatty acid composition can effectively alter the fatty acid distribution of LDL and HDL in hypercholesterolemic subjects and that susceptibility to LDL oxidation is altered by these changes. Substitution of monounsaturated (rather than polyunsaturated) fatty acids for saturated fatty acids in the diet might be preferable for the prevention of atherosclerosis. (J. Clin. Invest. 1993. 91:668-676.) Key words: atherosclerosis • macrophages • conjugated dienes $\cdot$ lipid oxidation • high density lipoprotein
\end{abstract}

\section{Introduction}

It has been proposed that oxidative modification of LDL may increase its atherogenicity $(1,2)$, and there is evidence that oxidative modification of LDL does occur in vivo (3-6). The generation of oxidatively modified LDL appears dependent on the peroxidative decomposition of its polyunsaturated fatty acids, yielding reactive aldehydes, some of which form covalent bonds with $\operatorname{LDL}$ apo $B(4,5,7,8)$, generating a modified $L D L$ recognized by the scavenger receptor(s) of the macrophage $(9$, 10). This leads to enhanced uptake and foam cell formation. In

Address correspondence to Peter Reaven, M.D., Department of Medicine, University of California, San Diego, 9500 Gilman Drive, La Jolla, CA 92093-0682. 1992.

Received for publication 27 April 1992 and in revised form 6 August

J. Clin. Invest.

(c) The American Society for Clinical Investigation, Inc. $0021-9738 / 93 / 02 / 0668 / 09 \$ 2.00$

Volume 91, February 1993, 668-676 addition, it is now apparent that oxidized LDL or soluble products formed during the oxidation of LDL have other biological effects including monocyte chemotaxis (1), cytotoxicity (11), alteration of gene expression in arterial cells $(12,13)$, and alteration of vascular tone (for review see reference 2 ).

Diets enriched in polyunsaturated fatty acids are considered to be beneficial because of their hypocholesterolemic effects (14-16). However, these diets lead to LDL particles enriched in polyunsaturated fatty acids $(17,18)$, which should be more susceptible to lipid peroxidation and, in principle, possibly more atherogenic $(1,2)$. Replacement of dietary saturated fatty acids with monounsaturated fatty acids has been shown to be as effective as replacement with polyunsaturated fatty acids in lowering plasma LDL levels $(14-16,18)$ and it has the advantage that it does not simultaneously lower HDL cholesterol levels $(15,16,19)$. HDL has also been demonstrated to inhibit the oxidative modification of LDL (20). Because there may be an exchange of fatty acids and oxidized fatty acids products between LDL and HDL, HDL particles enriched with polyunsaturated fatty acids may offer less protection to LDL. Thus, diets enriched in monounsaturated fats rather than polyunsaturated fats might confer additional protection by generating both LDL particles that are more resistant to oxidation and HDL particles that inhibit oxidative modification, while optimizing both LDL and HDL cholesterol levels.

In a pilot study, we recently demonstrated that LDL isolated from normocholesterolemic subjects fed a monounsaturated-enriched diet was less susceptible to oxidation and modifcation (18). In the current study we evaluated the effects of extended feeding of mono- versus polyunsaturated-enriched diets to mildly hypercholesterolemic subjects on LDL oxidation and modification. In addition, we studied both the changes in overall fatty acid composition and in individual lipid fractions produced by oxidation. Finally, we show that monounsaturated-rich diets do not alter the ability of HDL to inhibit LDL oxidation.

\section{Methods}

Participants. 13 healthy hypercholesterolemic volunteers ( 7 women and 6 men), aged 20-59 yr, were recruited from the community. All were on average American diets. None were taking medications or vitamins at the time of recruitment. The study was approved by the Human Studies Committee of the University of California, San Diego, and was conducted in the outpatient facilities of the University of California, San Diego, General Clinical Research Center.

Study design. An oleate-enriched variant of sunflower oil (Trisun 80 ), provided by SVO Enterprises (Eastlake, $\mathrm{OH}$ ), and conventional sunflower oil, Wesson Sunlite, provided by Hunt Wesson (Fullerton, CA), were used to prepare liquid diets as described by Mattson and Grundy (16). Oleate accounts for $>80 \%$ of the total fatty acids in Trisun 80 whereas regular sunflower oil is $\sim 60 \%$ linoleate. Vitamin E 
content of the Trisun 80 used in this study was $0.538 \mathrm{mg} / \mathrm{g}$ oil whereas that of the sunflower oil used was $0.512 \mathrm{mg} / \mathrm{g}$ oil. Liquid diets were prepared by the General Clinical Research Center Nutrition Unit and provided $40 \%$ of calories as fat, $45 \%$ as carbohydrates, and $15 \%$ as protein. Diet ingredients and composition were as previously described (18). Initial daily caloric intake for each individual was calculated from estimates of energy requirements, on the basis of 3-d food records and standard nomogram values (21) for each individual. Each liquid diet varied only in the percentage of monounsaturated or polyunsaturated fatty acids. These diets, aside from small amounts of vegetables and other nonfat snacks, which accounted for $<300 \mathrm{kcal}$, were used exclusively as the source of nutrition for the study participants for $6 \mathrm{~d}$ of each week. During these $6 \mathrm{~d}$ essentially all fat intake was supplied by the liquid diet. To improve adherence to the study diet, subjects were allowed to eat solid food of their choice one weekend day each week from recommended food lists and sample meal menus. Foods that were recommended for ingestion during this "off day" were low in fat and low in vitamin $E$ and beta-carotene. Dietary records were reviewed weekly by a registered dietitian to ensure adherence to the recommended food guidelines. Total daily energy intake for each individual was adjusted weekly as needed to maintain body weight.

Subjects were randomized to either polyunsaturate- $(n=7)$ or monounsaturate- $(n=6)$ supplemented liquid diets. Subjects remained blinded to the predominate type of fatty acid present in their diet throughout the study. Participants picked up their fully prepared liquid diets on Monday, Wednesday, and Friday of each week for the total 8-wk study period. Unused portions of diet were returned at each visit. Each participant was allowed to ingest their daily liquid diet according to their own schedule, although the entire day's allocation was to be ingested by bedtime. Subjects were instructed to refrigerate the liquid diets at all times when not in use. Aliquots of the diet were analyzed biweekly to check stability of fatty acid composition. During the study all participants were supplied with a daily multivitamin (Centrum, P. Leiner Nutritional Products, Inc., Torrance, CA).

Preparation of $L D L$. Fasting blood samples were obtained from each subject at two baseline visits before initiation of the liquid diet and at completion of the 8-wk dietary period. Blood was collected in EDTA $(4.0 \mathrm{mM})$, placed immediately on ice, and the plasma was separated. LDL was isolated by sequential ultracentrifugation as previously described (18) and dialyzed extensively against PBS containing $0.27 \mathrm{mM}$ EDTA (PBS-EDTA). A final concentration of $0.22 \mathrm{mM}$ gentamycin, $0.15 \mathrm{mM}$ chloramphenicol, $1 \mu \mathrm{M}$ D-phenylalanyl-L-prolyl-L-arginine chloromethyl ketone, and $2 \mathrm{mM}$ benzamidine was added to plasma and all solutions used subsequently during LDL isolation. Protein was determined by the method of Lowry et al. (22). Measurement of LDLconjugated diene and lipid peroxide formation during $\mathrm{Cu}^{2+}$-mediated oxidation was carried out immediately, as described below. All other studies were completed within 2 wk of isolation of LDL samples, which were stored at $4^{\circ} \mathrm{C}$ in the dark. LDL protein from each plasma sample was radioiodinated by the method of Salacinski et al. (23) and the specific activity of each was adjusted to $\sim 30,000$ counts $\cdot$ min per $\mu \mathrm{g}$ protein by addition of their own unlabeled LDL. For all assays, LDL samples were adjusted to similar protein concentrations with PBSEDTA. Thus each sample had an equal concentration of protein with equal specific activity and equal EDTA content per sample for each experiment.

Vitamin E content. Alpha-tocopherol was measured by HPLC according to a modification of methodology described by Kaplan (24). Briefly, alpha-tocopherol acetate was prepared in $100 \%$ ethanol at 58 $\mu \mathrm{mol} /$ liter as an extraction internal standard and for standard curve preparation. Actual concentrations of alpha-tocopherol were determined by measuring absorbance of prepared solutions and calculating concentrations on the basis of known spectral data (25). Plasma and LDL samples were extracted with petroleum ether and evaporated under nitrogen. The extract was reconstituted in a mobile phase that consisted of acetonitrile, chloroform, 2-propanol, water (78:16:3.5:2.5; $\mathrm{vol} / \mathrm{vol} / \mathrm{vol} / \mathrm{vol}$ ) and run at a flow rate of $2 \mathrm{ml} / \mathrm{min}$. The chromatographic analysis was performed on a $5-\mu \mathrm{m}$ particle $\mathrm{C}-18$ column. Cal- culations were determined from a standard curve of peak area ratios of sample/internal standard.

Oxidation of $L D L$. The formation of conjugated dienes was measured by incubating $200 \mu \mathrm{g}$ of LDL protein with $5 \mu \mathrm{mol} /$ liter copper sulfate $\left(\mathrm{Cu}^{2+}\right)$ in $2 \mathrm{ml}$ of Ham's F-10 medium. The absorbance at 234 $\mathrm{nm}\left(\mathrm{A}_{234}\right)$ was measured continuously in a Uvikon 810 spectrophotometer (Kontron Instruments, Basel, Switzerland) as described $(18,26)$. Results are expressed as absolute increase in absorbance above the initial value. The formation of lipid peroxides was measured by the iodometric method (27). LDL was incubated at $100 \mu \mathrm{g} / \mathrm{ml}$ in PBS with 5 $\mu \mathrm{mol} /$ liter $\mathrm{Cu}^{2+}$ at $37^{\circ} \mathrm{C}$ and aliquots were removed for lipid peroxide measurement at $0,2,4,6$, and $8 \mathrm{~h}$.

Each subject's ${ }^{125}$ I-labeled LDL, at a concentration of $100 \mu \mathrm{g}$ protein $/ \mathrm{ml}$, was incubated with $5 \mu \mathrm{mol} /$ liter $\mathrm{Cu}^{2+}$ for 0 and $8 \mathrm{~h}$ or with monolayers of rabbit aortic endothelial cells (EC) ${ }^{1}$ in Ham's F-10 medium for 0,8 , and $16 \mathrm{~h}$ at $37^{\circ} \mathrm{C}$ as previously described (9). Lipid peroxidation was assessed in terms of thiobarbituric acid-reactive substance (TBARS) in the medium (9). Results are expressed as malondialdehyde equivalents per $\mathrm{mg}$ of LDL protein.

$L D L$ degradation and uptake. To evaluate one parameter of biological modification of LDL induced by in vitro oxidation, we measured the macrophage degradation of each individual iodinated LDL sample. Resident mouse macrophages were harvested from the peritoneal cavity by lavage and plated on 24-well clustered dishes at a density of $\sim 1.4 \times 10^{6}$ cells per well with RPMI medium containing $10 \%$ (vol/ vol) fetal calf serum as previously described (9). After an overnight incubation, the medium was replaced and degradation by macrophages of $5 \mu \mathrm{g}{ }^{125} \mathrm{I}-\mathrm{LDL}$ protein $/ \mathrm{ml}$ medium for $5 \mathrm{~h}$ at $37^{\circ} \mathrm{C}$ was determined as previously described (18).

Fatty acid composition. Lipids from $\mathrm{LDL}$ and $\mathrm{HDL}$ and from aliquots of the different diets were extracted by a modification of the method of Folch et al. (28). The fatty acids were transmethylated and analyzed in a gas chromatograph (model 3700, Varian Associates, Sugenland, TX) equipped with a column of $10 \%$ Silar 5CP on a Gas Chrom QII, 100/120 mesh (Alltech Associates, Inc, Deerfield, IL). For quantitative estimates of total fatty acids present in LDL, a 15:0 internal standard (pentadecanoic acid) was added to each sample before extraction. Calculations of fatty acid amounts were determined from peak area ratios of sample to internal standard. In these samples, fatty acids longer than 20:4 were only present in small amounts (a combined total of $<3 \%$ ) and were not used for these calculations. For analyses of fatty acids in lipid fractions, the cholesteryl esters, triglycerides, and phospholipids were separated on prewashed silica gel G TLC plates using a solvent system of petroleum ether/ethyl ether/acetic acid (80:20:0.7; vol/vol/vol). Each lipid fraction was then scraped from the plate and methylated directly for fatty acid determinations. The 15:0 internal standard was added directly to the scraped silica gel. As recovery averaged from 70 to $90 \%$ for all the different lipid fractions, values were adjusted up to $100 \%$ recovery based on total original measurement of LDL cholesteryl ester, triglyceride, and phospholipid content. Cholesteryl esters (29) and triglycerides (30) were measured enzymatically and phospholipids were measured for total phosphorous (31).

Effect of oxidation on fatty acid composition of fractionated $L D L$. At the end of the 8-wk study period, total fatty acid analyses were performed on each LDL sample before and after incubation with $\mathrm{Cu}^{2+}$ for $16 \mathrm{~h}$ as described above. To determine the effect of oxidation on the fatty acid composition of the individual lipid classes of LDL, cholesteryl ester, phospholipid, and triglyceride fractions were separated by TLC and fatty acid analyses were performed on each fraction after $16 \mathrm{~h}$ of $\mathrm{Cu}^{2+}$-mediated oxidation in LDL samples from a subset of each dietary group. Additionally, in LDL from three control subjects, similar analyses were performed on aliquots removed at frequent intervals during $24 \mathrm{~h}$ of $\mathrm{Cu}^{2+}$-mediated oxidation.

1. Abbreviations used in this paper: EC, endothelial cells; TBARS, thiobarbituric-acid-reactive substances. 
Table I. Comparison of Weight, Cholesterol, and Triglyceride Values at Baseline and Study Completion in Oleate and Linoleate Groups*

\begin{tabular}{|c|c|c|c|c|c|c|c|c|c|c|}
\hline \multirow[b]{2}{*}{ Diet } & \multicolumn{2}{|c|}{ Body weight } & \multicolumn{2}{|c|}{ Total cholesterol } & \multicolumn{2}{|c|}{ LDL cholesterol } & \multicolumn{2}{|c|}{ HDL cholesterol } & \multicolumn{2}{|c|}{ Triglycerides } \\
\hline & Baseline & Final & Baseline & Final & Baseline & Final & Baseline & Final & Baseline & Final \\
\hline & \multicolumn{2}{|c|}{$k g$} & \multicolumn{8}{|c|}{$m g / d l$} \\
\hline Linoleate $(n=7)$ & $76.8 \pm 9.2$ & $74.2 \pm 8.0^{\ddagger}$ & $218.0 \pm 16.1$ & $171.9 \pm 21.9^{\ddagger}$ & $135.6 \pm 16.7$ & $102.3 \pm 18.1^{\ddagger}$ & $63.0 \pm 21.8$ & $56.6 \pm 14.9$ & $99.0 \pm 39.5$ & $65.3 \pm 26.8^{\ddagger}$ \\
\hline Oleate $(n=6)$ & $72.3 \pm 17.2$ & $70.0 \pm 17.0^{\ddagger}$ & $228.7 \pm 31.1$ & $199.7 \pm 17.2^{\ddagger}$ & $143.3 \pm 33.5$ & $116.8 \pm 14.4^{\ddagger}$ & $61.9 \pm 14.4$ & $58.2 \pm 15.6^{\ddagger}$ & $116.8 \pm 28.8$ & $123.2 \pm 52.3$ \\
\hline
\end{tabular}

*Values given are mean \pm SD. ${ }^{\ddagger}$ Significant compared with the baseline value, $P<0.05$.

HDL assays. HDL fatty acid composition was determined by the identical methodology used for LDL. In addition, HDL samples (at 50 and $100 \mu \mathrm{g} / \mathrm{ml}$ Ham's F-10 medium) were coincubated with ${ }^{125} \mathrm{I}-\mathrm{LDL}$ during $\mathrm{Cu}^{2+}$-mediated oxidation to assess their ability to inhibit macrophage degradation of LDL (20). Degradation by macrophages of $5 \mu \mathrm{g}$ ${ }^{125} \mathrm{I}-\mathrm{LDL}$ protein $/ \mathrm{ml}$ medium for $5 \mathrm{~h}$ at $37^{\circ} \mathrm{C}$ was determined as described above.

Statistical analyses. Comparisons between dietary group means were performed by Student's unpaired $t$ test; baseline and final means within dietary groups were compared by Student's paired $t$ tests. Repeated-measures analysis of variance was used to compare overall mean $\mathrm{A}_{234}$ over time between groups at study completion. Pearson's correlation coefficient was used to measure the association between $A_{234}$, macrophage degradation, and content of selected fatty acids in LDL.

\section{Results}

All participants completed the 8-wk liquid diet study without significant problems. One participant (subject 1 ) on the oleate diet had persistent gastrointestinal discomfort and throughout the study ingested a reduced volume of her liquid diet. Weekly food records and measurement of unused portions of the liquid diet indicated compliance was excellent in all other participants, with $>95 \%$ of the provided liquid diet ingested by each participant. Total tocopherol levels in the Trisun $₫ 80$ oil $(0.538 \mathrm{mg} / \mathrm{gm})$ and in the Wesson Sunlite oil $(0.512 \mathrm{mg} / \mathrm{g})$ were similar. Fatty acid analyses of dietary samples, performed biweekly throughout the study, indicated that the fatty acid composition of the oleate-enriched diet was $78 \%$ oleic acid (18:1), 13\% linoleic acid (18:2), 4.5\% stearic acid (18:0), and $4.5 \%$ palmitic acid (16:0). In contrast, fatty acid composition of the linoleate-enriched diet averaged 24\% 18:1, 63\% 18:2, $5.0 \% 18: 0$, and $8 \% 16: 0$. The calculated average total energy intake from the liquid diet was $2,673 \pm 870 \mathrm{kcal} / \mathrm{d}$ for the oleate group and $2,683 \pm 372 \mathrm{kcal} / \mathrm{d}$ for the linoleate group. During the $6 \mathrm{~d} / \mathrm{wk}$ when the liquid diet was supplied, subjects ingested on average $300 \mathrm{kcal} / \mathrm{d}$ from nonliquid diet sources with $<70$ $\mathrm{kcal} / \mathrm{d}$ in the form of fat. Caloric intake on the one "off-day" averaged $1,733 \pm 620 \mathrm{kcal} / \mathrm{d}$ for the oleate group and $1,943 \pm 1,046 \mathrm{kcal} / \mathrm{d}$ for the linoleate group with energy intake in the form of fat only $\sim 15 \%$ of total calories for both groups. Mean baseline and final weights and lipids are shown in Table I. Weight decreased by $\sim 3 \%$ in each group. Total cholesterol decreased significantly in both study groups and LDL cholesterol decreased $24.5 \%$ in the linoleate group and $18.5 \%$ in the oleate group. HDL cholesterol decreased by $10 \%$ and $6 \%$ in the linoleate and oleate groups, respectively. LDL vitamin E levels (per mg LDL protein) were not different in the two dietary groups at either baseline or at the end of the study (baseline: oleate group vs. linoleate group, $5.6 \pm 0.8$ vs. $5.4 \pm 1.1 \mu \mathrm{g} / \mathrm{mg}, P$
$=0.7$; final: oleate group vs. linoleate group, $6.8 \pm 1$ vs. $7.0 \pm 0.6$ $\mu \mathrm{g} / \mathrm{mg}, P=0.7$ ).

Fatty acid composition of $L D L$. Before starting the special diets there were no significant differences in the percent distribution of any long-chain fatty acids in the LDL isolated from the two study groups (Table II). After 8 wk of linoleate (18:2) or oleate (18:1) dietary enrichment, however, mean levels of 18:2 and 18:1 had increased significantly, as expected ( $P$ $<0.001)$. Small but significant changes between the two groups also occurred in the relative content of 18:0 and 20:4. Within the oleate dietary group, five of six subjects had increases in oleic acid $>60 \%$ and decreases in linoleic acid ranging from 8 to $30 \%$. However, the LDL of subject 1 (who tolerated $<50 \%$ of her liquid diet) showed only minimal changes in fatty acids composition. In the linoleate diet group, six of seven participants had marked decreases in 18:1 and increases in 18:2. The LDL of subject 12 had minimal changes in 18:1 and $18: 2$.

Thus 11 of the 12 study subjects who ingested the majority of their assigned liquid diet (throughout the study) had substantial changes in their LDL fatty acid content, which reflected the composition of their diet. The reason subject 12 did not have comparable LDL changes is unknown.

Effects of diet on parameters of $L D L$ oxidation. The rate and extent of conjugated diene formation was consistent for each individual LDL sample when incubated at room temperature in the presence of $5 \mu \mathrm{mol} / \mathrm{L} \mathrm{Cu}^{2+}$. The data shown represent the mean of results of LDL isolated from each of the subjects. At baseline there was no difference in absorbance at 234 nm (Fig. $1 A$ ) of LDL from the two study groups. However, after 8 wk of dietary enrichment, the mean absolute increase in

Table II. Percent of Total Fatty Acids in LDL

\begin{tabular}{crrrrr}
\hline & \multicolumn{2}{c}{$\begin{array}{c}\text { Oleate diet } \\
(n=6)\end{array}$} & & \multicolumn{2}{c}{$\begin{array}{c}\text { Linoleate diet } \\
(n=7)\end{array}$} \\
\cline { 2 - 3 } \cline { 6 - 7 } Fatty acid & \multicolumn{1}{c}{ Baseline } & Final & & Baseline & Final \\
\hline & & & & & \\
$16: 0$ & $22.5 \pm 1.1$ & $18.8 \pm 2.1$ & & $21.4 \pm 1.6$ & $17.9 \pm 2.2$ \\
$16: 1$ & $1.9 \pm 0.4$ & $1.8 \pm 0.6$ & & $2.6 \pm 0.6$ & $1.0 \pm 0.4$ \\
$18: 0$ & $9.0 \pm 1.8$ & $6.4 \pm 0.9$ & & $7.5 \pm 1.5$ & $7.3 \pm 0.5^{*}$ \\
$18: 1$ & $15.6 \pm 1.5$ & $26.6 \pm 4.0$ & & $17.9 \pm 2.1$ & $10.7 \pm 1.8^{\ddagger}$ \\
$18: 2$ & $39.4 \pm 4.1$ & $36.8 \pm 2.8$ & & $39.2 \pm 2.9$ & $55.2 \pm 4.0^{\ddagger}$ \\
$20: 4$ & $11.6 \pm 2.2$ & $9.6 \pm 0.8$ & & $11.4 \pm 2.2$ & $7.9 \pm 1.4^{*}$ \\
\hline
\end{tabular}

Comparison between dietary groups of the content of fatty acids as a percent of total fatty acids in LDL. Data are presented as means \pm SD. No significant differences were present between groups at baseline.

* Significant compared with the oleate group final value, $P<0.05$.

‡ Significant compared with the oleate group final value, $P<0.001$. 


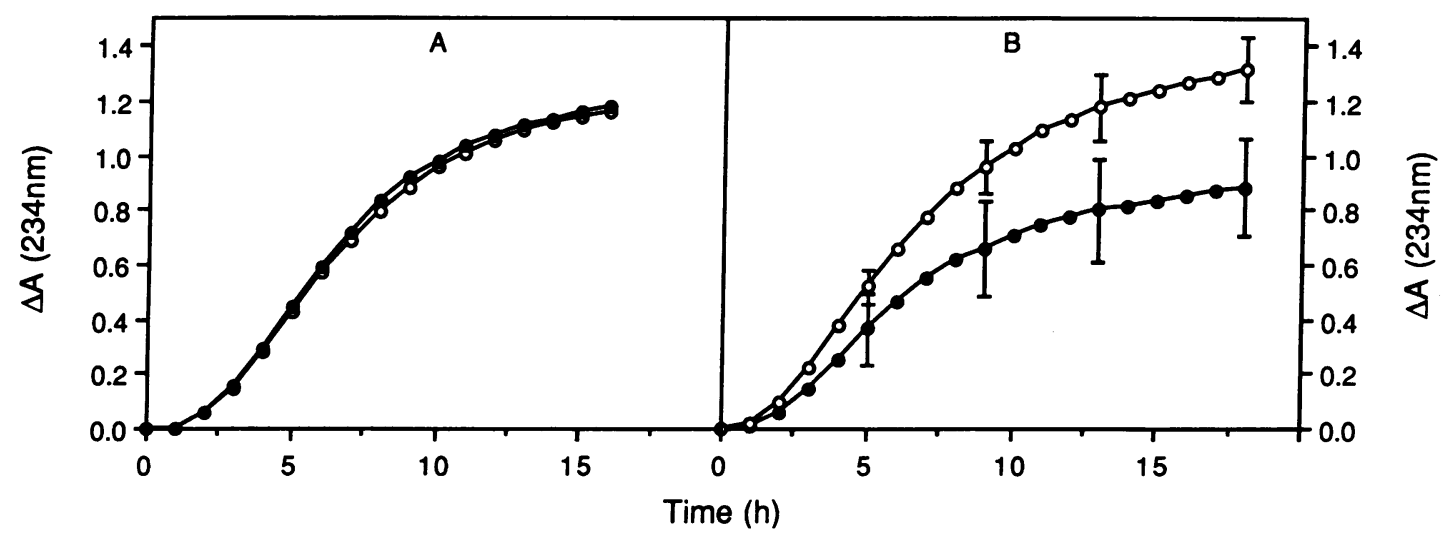

Figure 1. Measurement of conjugated diene formation in LDL after $\mathrm{Cu}^{2+}$-induced oxidation. $\mathrm{LDL}(100 \mu \mathrm{g} / \mathrm{ml})$ samples from subjects on oleate( shaded, $n=6$ ) or linoleate- (open, $n=7$ ) supplemented diets were incubated in Ham's F-10 medium containing $5 \mu \mathrm{mol} /$ liter $\mathrm{Cu}^{2+}$ at room temperature and absorbance at $234 \mathrm{~nm}$ was measured at hourly intervals in a Uvikon 810 spectrophotometer. Mean values \pm SD measured on LDL samples isolated at baseline are shown in $A$ whereas values measured on LDL samples isolated at the end of the study are shown in $B$.

$\mathrm{A}_{234}$ after $18 \mathrm{~h}$ of oxidation was $50 \%$ greater in the linoleatesupplemented group (Fig. $1 \mathrm{~B}$ ). Repeated-measures analysis of variance was used to compare the overall absorbance over time between the dietary groups and revealed a significant difference $(P<0.001)$. Finally, the absolute change in absorbance $\left(\Delta \mathrm{A}_{234}\right)$ strongly correlated with the percent of 18:2 in LDL ( $r$ $=0.89, P<0.05)$. A similarly strong but inverse correlation was present between $\Delta \mathrm{A}_{234}$ and the percent of 18:1 in LDL ( $r$ $=-0.82, P<0.05)$.

The time course of LDL lipid peroxide formation during $\mathrm{Cu}^{2+}$-mediated oxidation is shown in Fig. 2. Mean levels of lipid peroxides were similar in both groups before oxidation, but levels after initiation of oxidation were higher in the linoleate group at each time point, with differences achieving statistical significance at 2,6 , and $8 \mathrm{~h}$.

At the beginning of the study, there were no significant differences in amount of TBARS formed as a result of $\mathrm{Cu}^{2+}$ or EC oxidation. However, after 8 wk of the study diet, TBARS generated during LDL oxidation were higher in the oleate group at each time point (Fig. 3, top).

Macrophage degradation. The extent of macrophage degradation of each ${ }^{125}$ I-labeled LDL sample, before and after oxida-

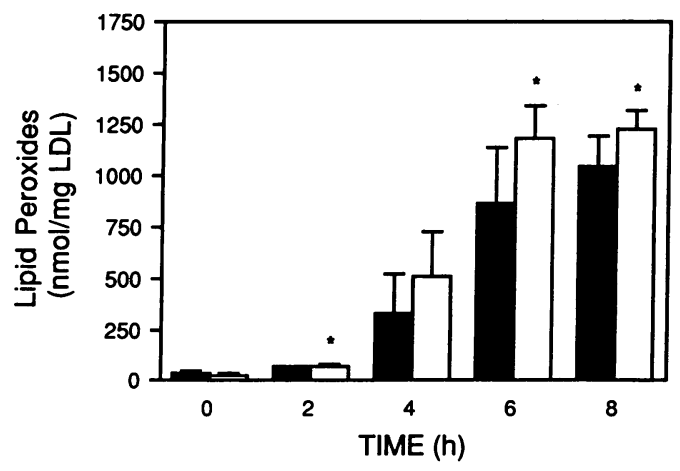

Figure 2. Measurement of lipid peroxides in $\mathrm{LDL}$ after $\mathrm{Cu}^{2+}$-induced oxidation. LDL $(100 \mu \mathrm{g} / \mathrm{ml})$ samples from subjects on oleate (shaded) or linoleate (open) supplemented diets were incubated in PBS with $5 \mu \mathrm{mol} /$ liter $\mathrm{Cu}^{2+}$ and aliquots were removed for measurement of lipid peroxides at $0,2,4,6$, and $8 \mathrm{~h}$. Means \pm SD are presented. *Significant difference compared with values for the oleate group, $P<0.05$. tion by $\mathrm{Cu}^{2+}$ or by EC was also measured. At the beginning of the study, comparison of LDL samples from the two groups showed no significant difference in the oxidation-induced increase in macrophage degradation (data not shown). At the end of the formula-diet period, the extent of LDL degradation by macrophages after $\mathrm{EC}$ or $\mathrm{Cu}^{2+}$ oxidation was significantly greater in the linoleate group at each oxidation time point (Fig.
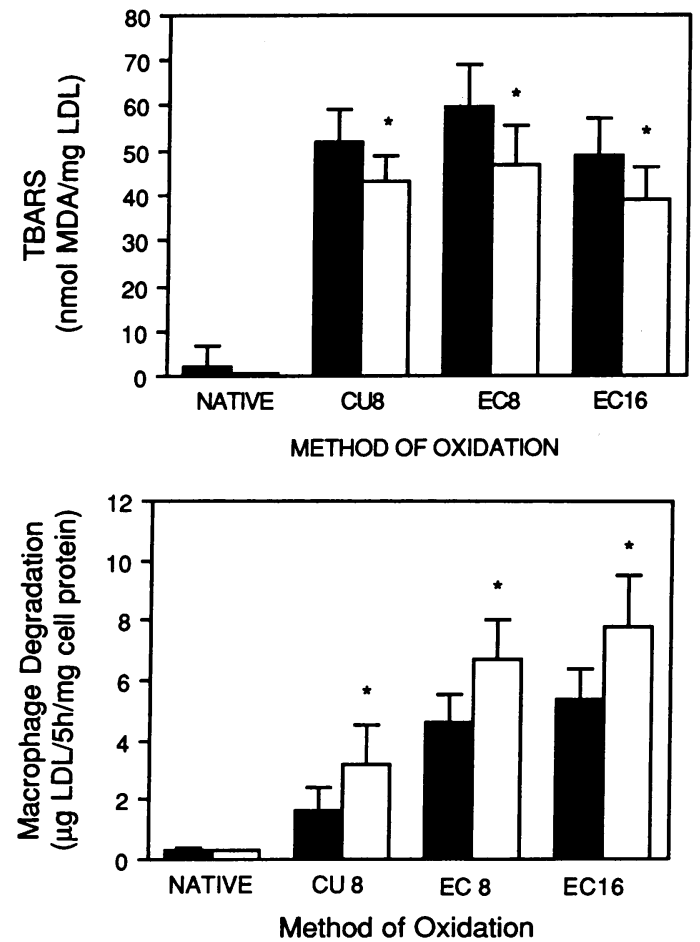

Figure 3. Measurement of generation of TBARS and macrophage degradation of LDL subjected to copper oxidation. Top: LDL ( 100 $\mu \mathrm{g} / \mathrm{ml}$ ) samples from subjects on oleate- (shaded) or linoleate- (open) supplemented diets were incubated with $5 \mu \mathrm{mol} /$ liter $\mathrm{Cu}^{2+}(8 \mathrm{~h})$ or endothelial cells $(8 \mathrm{~h})$ and $(16 \mathrm{~h})$ and TBARS measured. Bottom: 5 $\mu \mathrm{g}$ aliquots of $\mathrm{LDL}$ from the above incubations were then used to measure macrophage degradation. Values presented are means \pm SD. *Significant difference compared with values for the oleate group, $P$ $<0.05$. 
Table III. Content of Fatty Acids in LDL at the End of the Dietary Period (before and after Oxidation)

\begin{tabular}{|c|c|c|c|c|}
\hline \multirow[b]{2}{*}{ Fatty acid } & \multicolumn{2}{|c|}{$\begin{array}{l}\text { Oleate diet } \\
\quad(n=6)\end{array}$} & \multicolumn{2}{|c|}{$\begin{array}{l}\text { Linoleate diet } \\
\quad(n=7)\end{array}$} \\
\hline & Unoxidized & Oxidized & Unoxidized & Oxidized \\
\hline & \multicolumn{4}{|c|}{$\mu \mathrm{g} / \mathrm{mg} L D L$ protein } \\
\hline $16: 0$ & $209.5 \pm 44.5$ & $182.0 \pm 34.2$ & $182.9 \pm 26.7$ & $152.7 \pm 26.7$ \\
\hline $16: 1$ & $20.7 \pm 9.0$ & $16.3 \pm 5.6$ & $10.4 \pm 4.1$ & $8.9 \pm 4.6$ \\
\hline $18: 0$ & $70.3 \pm 4.9$ & $60.7 \pm 3.9$ & $74.1 \pm 4.6$ & $59.8 \pm 4.5$ \\
\hline $18: 1$ & $293.6 \pm 51.2$ & $241.0 \pm 44.1$ & $110.4 \pm 22.1$ & $82.2 \pm 23.5$ \\
\hline $18: 2$ & $408.9 \pm 70.9$ & $79.8 \pm 21.5$ & $565.0 \pm 66.7$ & $78.3 \pm 27.4$ \\
\hline $20: 4$ & $105.0 \pm 8.0$ & $6.5 \pm 3.9$ & $80.1 \pm 14.8$ & $7.8 \pm 5.8$ \\
\hline Total & $1108 \pm 147$ & $586 \pm 64$ & $1022 \pm 76$ & $389 \pm 81$ \\
\hline
\end{tabular}

Comparison of the content of fatty acids present in LDL isolated at the end of the study period from subjects on oleate- or linoleateenriched diets. Values presented represent means \pm SD of each fatty acid present in the LDL samples before and after $\mathrm{Cu}^{2+}$-mediated oxidation.

3 , bottom). Additionally, cell-associated ${ }^{125} \mathrm{I}$-labeled LDL was greater in the linoleate group (data not shown). In the entire study group, degradation of LDL, oxidized by either EC or $\mathrm{Cu}^{2+}$ (for $8 \mathrm{~h}$ ) was highly correlated with the percent 18:2 in LDL $(r=0.73, r=0.68$, respectively, $P<0.01)$ and percent 18:1 $(r=-0.77, r=-0.73$, respectively, $P<0.01)$. LDL degradation (after both $\mathrm{Cu}^{2+}$ and EC oxidation) also correlated with the ratio of percent 18:2 to percent 18:1 $(r=0.77, P<0.01)$.

Effects of oxidation on LDL fatty acid composition. At the end of the study, quantitative determinations of fatty acids were performed on all LDL samples from each dietary group before and after $16 \mathrm{~h}$ of $\mathrm{Cu}^{2+}$-mediated oxidation (Table III). At the end of the formula-diet period, LDL from the linoleate group showed an absolute increase in the amount of 18:2 and a decrease in 18:1. In response to oxidation, marked decreases in the content of 18:2 and 20:4 occurred in LDL from both dietary groups but there was a greater overall percent loss of total fatty acids in the LDL from the linoleate group (62.4 vs. $47.0 \%$, $P<0.01$ ).
The distribution of individual fatty acids in each lipid fraction was determined in LDL samples from four individuals from each dietary group at the end of $8 \mathrm{wk}$ (Table IV). In the cholesteryl ester and triglyceride core of the LDL particle, the majority of the fatty acids were mono- or polyunsaturated (18:1, 18:2, and 20:4). In contrast, in the surface-associated phospholipids, the saturated fatty acids (16:0 and 18:0) were most prevalent. There was enrichment of oleate in all three lipid classes in the oleate-fed group and corresponding increases in linoleate were seen in the linoleate-fed group. Particularly striking was the $18: 2 / 18: 1$ ratio in the cholesteryl ester fraction, which was 1.4 in the oleate-fed group and 4.7 in the linoleate-fed group. The diets did not cause a change in the distribution of a given fatty acid between the core and surface lipids: i.e., although there was a greater absolute amount of oleic acid in LDL, its distribution between triglycerides, cholesteryl ester, and phospholipid did not change (data not shown).

To determine whether the degradation of polyunsaturated fatty acids during oxidation was influenced by their location within the LDL particle, quantitative determinations of fatty acids were performed on the separated cholesteryl ester, triglyceride, and phospholipid fractions of LDL isolated from several individuals from each dietary group before and after $16 \mathrm{~h}$ of $\mathrm{Cu}^{2+}$ oxidation (Table $\mathrm{V}$ ). The greatest loss of unsaturated fatty acids was in the core (cholesteryl ester and triglyceride fractions) and the loss of polyunsaturated fatty acids was nearly complete. Monounsaturated fatty acids associated with phospholipids, however, were relatively stable. There was little loss of 16:0 and 18:0 saturated fatty acids (data not shown). This was true for LDL isolated from both dietary groups. To characterize the location and rates of fatty acid loss in individual lipid fractions, fatty acid analyses were performed on three control LDL samples during a 24-h incubation with $\mathrm{Cu}^{2+}$. Aliquots were analyzed for the quantity of $18: 1,18: 2$, and 20:4 present in the total LDL sample as well as in cholesteryl ester and phospholipid fractions (Fig. 4). As shown in Fig. $4 \mathrm{~A}$, the total 18:2 and 20:4 content in LDL decreased rapidly after several hours of oxidation. The amount of 18:1 in contrast, decreased more slowly with significant loss apparent only after $\sim 16 \mathrm{~h}$ of oxidation. Different patterns of fatty acid loss were observed in the core (cholesteryl ester) and surface (phospholipids) under these conditions of oxidation. In the phospholipid fraction

Table IV. Effects of Diets on Distribution of Fatty Acids in LDL Lipid Fractions

\begin{tabular}{|c|c|c|c|c|c|c|}
\hline \multirow[b]{2}{*}{$\begin{array}{l}\text { Fatty } \\
\text { acid }\end{array}$} & \multicolumn{2}{|c|}{ Cholesteryl ester } & \multicolumn{2}{|c|}{ Triglyceride } & \multicolumn{2}{|c|}{ Phospholipid } \\
\hline & $\begin{array}{c}\text { Oleate } \\
\text { diet }\end{array}$ & $\begin{array}{c}\text { Linoleate } \\
\text { diet }\end{array}$ & $\begin{array}{c}\text { Oleate } \\
\text { diet }\end{array}$ & $\begin{array}{c}\text { Linoleate } \\
\text { diet }\end{array}$ & $\begin{array}{c}\text { Oleate } \\
\text { diet }\end{array}$ & $\begin{array}{c}\text { Linoleate } \\
\text { diet }\end{array}$ \\
\hline & \multicolumn{6}{|c|}{ \% distribution } \\
\hline $16: 0$ & $12.0 \pm 1.5$ & $14.2 \pm 0.7$ & $21.7 \pm 3.6$ & $27.7 \pm 1.5$ & $40.3 \pm 4.8$ & $42.2 \pm 2.1$ \\
\hline $16: 1$ & $2.1 \pm 0.7$ & $1.4 \pm 0.2$ & $3.5 \pm 0.7$ & $3.0 \pm 0.2$ & - & - \\
\hline $18: 0$ & $0.8 \pm 0.2$ & $1.3 \pm 0.1$ & $4.1 \pm 0.2$ & $7.1 \pm 1.4$ & $19.0 \pm 2.5$ & $23.8 \pm 0.6$ \\
\hline $18: 1$ & $32.0 \pm 5.6$ & $13.8 \pm 0.8$ & $58.6 \pm 5.3$ & $37.0 \pm 0.8$ & $20.0 \pm 1.7$ & $9.2 \pm 0.5$ \\
\hline $18: 2$ & $45.4 \pm 7.5$ & $64.9 \pm 3.1$ & $8.0 \pm 5.8$ & $21.2 \pm 3.6$ & $15.1 \pm 4.6$ & $19.3 \pm 1.6$ \\
\hline $20: 4$ & $7.4 \pm 4.1$ & $4.4 \pm 1.7$ & $4.1 \pm 1.9$ & $3.4 \pm 0.2$ & $5.6 \pm 1.9$ & $5.6 \pm 1.6$ \\
\hline
\end{tabular}

Percent distribution of fatty acids in each lipid fraction from four LDL samples from each dietary group. Data are presented as means \pm SD. Values that were too small to be reliably detected were not included. The data may underestimate the overall percent of polyunsaturated fatty acids present in the phospholipid fraction as during the lengthy isolation and dialysis steps in the separation of LDL some of the polyunsaturated fatty acids in phospholipids may have already been lost as a result of oxidation. 
Table V. Fatty Acid Content of LDL Lipid Fractions Pre- and Postoxidation

\begin{tabular}{|c|c|c|c|c|c|c|c|}
\hline \multirow[b]{2}{*}{ Subject } & \multirow{2}{*}{$\begin{array}{l}\text { Fatty } \\
\text { acid }\end{array}$} & \multicolumn{2}{|c|}{ Cholesteryl ester } & \multicolumn{2}{|c|}{ Triglyceride } & \multicolumn{2}{|c|}{ Phospholipid } \\
\hline & & PRE-OX* & POST-OX & PRE-OX & POST-OX & PRE-OX & POST-OX \\
\hline & \multicolumn{7}{|c|}{$\mu g / m l L D L$} \\
\hline \multicolumn{8}{|c|}{ Linoleate dietary group } \\
\hline 8 & $18: 1$ & 75.0 & 36.2 & 66.7 & 4.1 & 31.4 & 40.9 \\
\hline 11 & & 87.0 & 27.0 & 33.5 & 2.0 & 38.4 & 52.5 \\
\hline 8 & $18: 2$ & 387.5 & 21.1 & 39.8 & 1.5 & 60.1 & 39.8 \\
\hline 11 & & 355.1 & 19.8 & 18.9 & 0.7 & 74.9 & 57.3 \\
\hline 8 & $20: 4$ & 18.5 & - & 6.0 & 4.2 & 12.5 & 4.2 \\
\hline 11 & & 40.0 & - & 29.4 & 2.4 & 20.0 & 7.1 \\
\hline \multicolumn{8}{|l|}{ Oleate group } \\
\hline 5 & $18: 1$ & 217.3 & 109.8 & 130.0 & 46.4 & 94.6 & 78.6 \\
\hline 6 & & 205.9 & 82.0 & 112.3 & 37.0 & 81.3 & 69.9 \\
\hline 5 & $18: 2$ & 224.5 & 13.6 & 11.8 & 3.0 & 58.5 & 28.2 \\
\hline 6 & & 238.9 & 12.4 & 7.5 & 2.9 & 40.3 & 21.7 \\
\hline 5 & $20: 4$ & 51.8 & 3.3 & 13.2 & 3.9 & 15.5 & - \\
\hline 6 & & 22.1 & - & 8.3 & 3.0 & 20.5 & 6.4 \\
\hline
\end{tabular}

Data presented are the specific values of each fatty acid as measured in each lipid fraction of LDL from two subjects on the linoleate-enriched diet and two subjects on the oleate-enriched diet. Values that were too small to be reliably detected were not included. * Oxidation.

(Fig. $4 C$ ) there was an immediate loss of 18:2 and 20:4, with continued rapid loss of 20:4 for up to $16 \mathrm{~h}$. Interestingly, the phospholipid 18:1 content did not significantly decrease during the 24-h oxidation period. In contrast, there was a delay before 18:2 and 20:4 loss occurred in the cholesteryl ester fraction (Fig. $4 \mathrm{~B}$ ). Subsequently, all the unsaturated fatty acids were lost at a rapid rate. There was also a nearly complete loss of $18: 1$ under these conditions of oxidation.

A

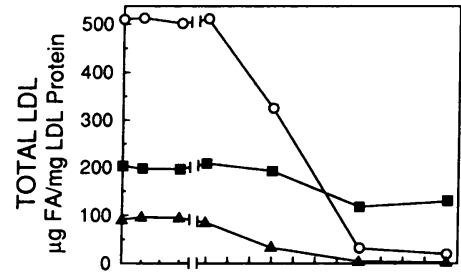

B

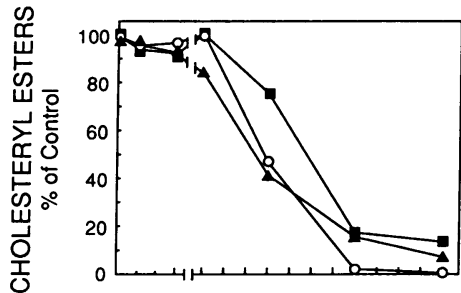

C

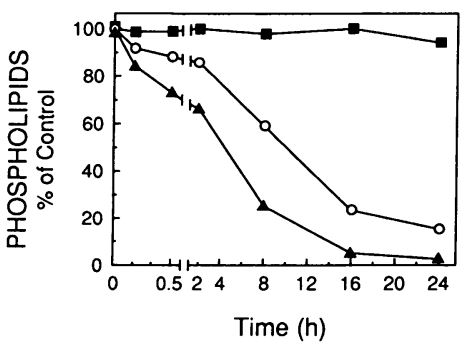

Figure 4. Effect of oxidation on LDL unsaturated fatty acids. LDL lipids were extracted and amounts of 18:1 (squares), 18:2 (circles) and 20:4 (triangles) measured before and during $(10,30$, and 120 $\min$ and 8,16 , and 24 h) $\mathrm{Cu}^{2+}$-mediated oxidation $(A)$. Data represent the mean values from three control LDL samples. Fatty acid analyses were also performed on TLC-separated cholesteryl ester $(B)$ and phospholipid fractions $(C)$. Data for $B$ and $C$ are presented as a percent of preoxidation values.
Effects of dietary manipulations on HDL. HDL was isolated from 10 of the 13 subjects after 8 wk of the study diet. The fatty acid composition of the HDL and its capacity to inhibit LDL modification was measured. The effects of the diets on HDL fatty acid composition were similar to those seen in LDL (Table VI). The percentage of 18:1 was significantly lower and the percentage of 18:2 was significantly higher in HDL isolated from the linoleate-fed subjects than in HDL isolated from the oleate-fed subjects. No significant differences were present in other fatty acids in the HDL fractions.

Parthasarathy et al. (20) previously demonstrated that HDL inhibits the oxidative modification of LDL in vitro. To evaluate whether this protective property of HDL was altered by the dietary-induced changes in HDL fatty acid composition, we performed a similar series of experiments using HDL samples from each dietary group. When HDL was incubated with LDL during $\mathrm{Cu}^{2+}$-mediated oxidation, the LDL was partially protected from oxidative modification, as evidenced by a de-

Table VI. Distribution of Total Fatty Acids in HDL

\begin{tabular}{lrc}
\hline Fatty acid & Oleate diet & Linoleate diet \\
\hline & & \\
$16: 0$ & $21.4 \pm 3.0$ & $20.1 \pm 1.2$ \\
$16: 1$ & $1.4 \pm 0.4$ & $1.0 \pm 0.2$ \\
$18: 0$ & $10.5 \pm 0.7$ & $12.7 \pm 0.7$ \\
$18: 1$ & $24.7 \pm 1.9$ & $11.0 \pm 1.5^{*}$ \\
$18: 2$ & $30.3 \pm 2.3$ & $44.6 \pm 2.2^{*}$ \\
$20: 4$ & $11.8 \pm 3.1$ & $10.6 \pm 1.0$
\end{tabular}

Comparison of the distribution of fatty acids as a percent of total fatty acids in HDL between dietary groups. Data are presented as means \pm SD of five HDL samples from each group. * Significant compared with the oleate group, $P<0.01$. 
crease in subsequent macrophage degradation. The effect was similar for HDL isolated from subjects in both dietary groups (Fig. 5).

\section{Discussion}

It has been well documented that hypercholesterolemia is both a common and important risk factor for coronary artery disease (32-34). Recommendations from a variety of expert panels, including The National Cholesterol Education Program, have stressed the need to lower cholesterol levels in people with hypercholesterolemia, initially with diet and subsequently, if needed, with medications (35). In general, dietary recommendations have been to decrease total dietary fat and cholesterol intake and to replace dietary saturated fats with polyunsaturated fats. More recently, however, studies have suggested that replacement of saturated fats with monounsaturated fats may be equally efficacious in lowering LDL cholesterol levels. In addition, monounsaturated fats have an advantage over saturated fats in that they do not appreciably lower HDL (14-16, 19). Our data provide an additional theoretical advantage for the preferential use of monounsaturated fats: such diets enrich lipoproteins with monounsaturated fatty acids and render them less susceptible to oxidative modification.

This study demonstrates that in mildly hypercholesterolemic subjects LDL and HDL fatty acid composition can be altered to reflect the fatty acid composition of the diet. Although the study diets were provided for $8 \mathrm{wk}$, LDL fatty acid analyses after $5 \mathrm{wk}$ of diet were essentially the same as those observed for the 8-wk samples (data not shown). This demonstrates that changes in LDL fatty acid composition occur relatively quickly, even in hypercholesterolemic subjects. Most importantly, LDL enriched in monounsaturated fatty acids and correspondingly reduced in polyunsaturated fatty acids was indeed more resistant to oxidative modification, as measured by several different parameters. This effect was directly related to the dietary-induced changes in LDL fatty acid composition. The study diets were essentially identical except for their fatty acid composition. Other potentially relevant variables, such as serum lipid values and LDL alpha-tocopherol levels, were similar between the two groups before and at the end of the study.

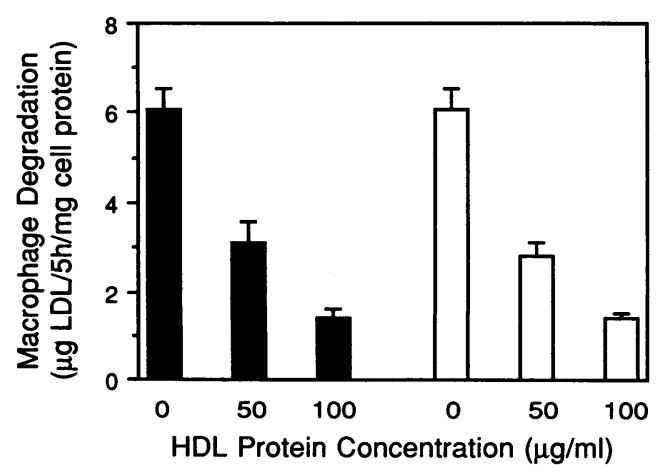

Figure 5. Ability of HDL to inhibit oxidative modification of LDL. ${ }^{125}$ I-labeled control LDL was incubated for $8 \mathrm{~h}$ with $5 \mu \mathrm{mol} / \mathrm{liter} \mathrm{Cu}^{2+}$ in the absence or presence of 50 or $100 \mu \mathrm{g}$ of HDL isolated from subjects on oleate- (shaded, $n=3$ ) or linoleate- (open, $n=3$ ) supplemented diets. 5- $\mu$ g aliquots of LDL from the above incubations were then used to measure macrophage degradation. Values presented are means $\pm \mathrm{SD}$.
Additionally, in the whole study group, measures of lipid peroxidation and LDL modification strongly correlated with the LDL 18:2 or 18:1 content. The relationship between LDL fatty acid composition and the extent of lipid oxidation (as measured by conjugated dienes) is summarized in Fig. 6, for subjects from both this study and our previous study of normocholesterolemic subjects (18). The extent of LDL oxidation, regardless of whether the LDL was isolated from normo- or hypercholesterolemic subjects, was strongly influenced by the percent of 18:2 in LDL.

As occurred in the previous study, TBARS generated during $\mathrm{Cu}^{2+}$ - or EC-mediated LDL oxidation did not reflect the extent of oxidation, as measured by conjugated diene formation, or the extent of apo B modification, as measured by macrophage degradation. In fact, in the present study, after oxidation of LDL, the levels of TBARS were higher in the monounsaturated group. It has been demonstrated previously that TBARS may not be a good measure of generalized lipid peroxide formation $(36,37)$. This is supported by our findings that lipid peroxide levels generated during LDL oxidation, when measured by an iodometric assay, were reduced in the monounsaturated group but measurement of TBARS was not. Esterbauer et al. (38) suggested that TBARS are primarily produced during the oxidation of arachidonic acid. Since arachidonic acid content was slightly higher in LDL from the oleate group, it is possible that the higher TBARS generated during oxidation of oleate-enriched LDL reflect the greater decomposition of arachidonic acid.

The rapid loss of phospholipid 18:2 and 20:4 after exposure to $\mathrm{Cu}^{2+}$ in the time course experiments (Fig. 4) indicates that the polyunsaturated fatty acids in the phospholipid surface are the first to undergo lipid oxidation. Subsequently, lipid oxidation extends into the LDL core where extensive loss of polyunsaturated fatty acid occurs. The discrepancy between the rate of loss of fatty acids in the core and periphery of the LDL is most apparent for oleic acid. The oleic acid present in the LDL phospholipid fraction, whether isolated from individuals consuming oleate-enriched, linoleate-enriched, or control diets, was virtually unchanged during prolonged oxidation. The cause of this difference in the rates of loss of oleic acid between core and

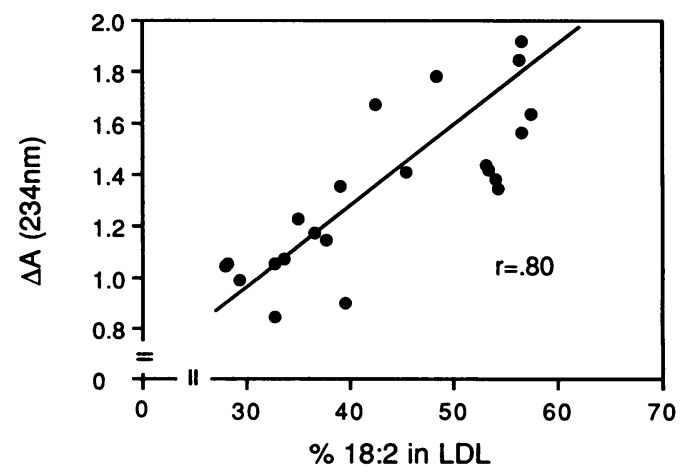

Figure 6. Correlation of conjugated diene formation with LDL content of linoleic acid. The absolute change in absorbance at $234 \mathrm{~nm}$ (representing conjugated diene formation) was correlated with linoleic acid content present in LDL after dietary supplementation in subjects from both the current and the previously described study (15) $(r=0.8, P<0.05)$. Absorbance was read after $16 \mathrm{~h}$ of LDL incubation in Ham's F-10 medium containing $5 \mu \mathrm{mol} /$ liter $\mathrm{Cu}^{2+}$ at room temperature. 
surface lipid fractions is unclear. Because each phospholipid molecule may contain only one polyunsaturated fatty acid, the surface phospholipid layer may be a more difficult environment in which to sustain propagation of lipid peroxidation. Hence, oleic acid, being inherently more resistant to oxidation than linoleic or arachidonic acid, may not be exposed to a sufficient concentration of peroxy radicals in the phospholipid layer to initiate hydroperoxy formation. In contrast, in the core of the LDL particle, which is enriched in linoleate in both cholesteryl esters and triglycerides, sufficient peroxy radical formation may occur to oxidize oleic acid as well.

In vitro it has been shown that a relatively high concentration of HDL can partially protect LDL from oxidative modification. Since HDL fatty acid composition was also markedly altered by the dietary manipulations during this study, it seemed important to evaluate the effect of this change on the ability of HDL to decrease LDL modification. HDL isolated from subjects on either diet, when used at a relatively high concentration, still retained its ability to inhibit LDL modification. Of course, it is unknown if this property of HDL contributes to its apparent in vivo antiatherosclerotic effect.

The results demonstrate quite clearly that the fatty acids in LDL that are most readily oxidized are 18:2 and 20:4. Oxidation of 18:1 also occurs, but to a lesser extent. Furthermore, the oxidation of 18:1 generates a relatively stable product, which, unlike polyunsaturated fatty acids, can generate only trace amounts of reactive aldehydes. Linoleic acid comprises from 35 to $50 \%$ of the total fatty acids in LDL and nearly $90 \%$ of the polyunsaturated fatty acids. The high content of 18:2 in LDL, its great abundance in the LDL core, and its capacity to easily undergo oxidation generating a wide array of reactive aldehydes and other products give this fatty acid a key role in LDL peroxidation. This study demonstrates that changes in dietary fatty acids can significantly alter LDL fatty acid composition in mildly hypercholesterolemic subjects. These are the individuals likely to benefit the most from dietary intervention. By decreasing the ratio of 18:2 to 18:1 in their LDL, it becomes less susceptible to in vitro oxidation and modification. It remains to be demonstrated that more practical diets can lead to similar findings and that this form of dietary intervention can slow or inhibit the development of atherosclerosis. Nevertheless, this study supports the concept that replacement of saturated fat with monounsaturated fat may reduce the risk for coronary artery disease both by lowering LDL levels and by decreasing the susceptibility of the LDL to oxidative modification.

\section{Acknowledgments}

We thank SVO Enterprises (Eastlake, $\mathrm{OH}$ ) for supplying Trisun ${ }^{\circledR}$ 80 oil and for additional financial support. We also thank Haven Webb and Felecidad Almazon for important assistance in the conduct of these studies and Annie Durning-Canting and Eva Brzezinski from the GCRC nutrition unit for excellent assistance in diet preparation and Lactaid Inc. (Pleasantville, $\mathrm{NJ}$ ) for providing Lactaid.

This work was supported by a grant from the NHLBI, HL-14197 (SCOR) and from a grant from the General Clinical Research Center (GCRC), National Institutes of Health MO1RR00827.

\section{References}

1. Steinberg, D., S. Parthasarathy, T. E. Carew, J. C. Khoo, and J. L. Witztum. 1989. Beyond cholesterol. Modifications of low-density lipoprotein that increase its atherogenicity. N. Engl. J. Med. 320:915-924.
2. Witztum, J. L., and D. Steinberg. 1991. Role of oxidized low density lipoprotein in atherogenesis. J. Clin. Invest. 88:1785-1792.

3. Haberland, M. E., D. Fong and L. Cheng. 1988. Malondialdehyde-altered protein occurs in atheroma of Watanabe heritable hyperlipidemic rabbits. Science (Wash. DC). 241:215-218.

4. Palinski, W., M. E. Rosenfeld, S. Ylä-Herttuala, G. C. Gurtner, S. A. Socher, S. W. Butler, S. Parthasarathy, T. E. Carew, D. Steinberg, and J. L. Witztum. 1989. Low density lipoprotein undergoes oxidative modification in vivo. Proc. Natl. Acad. Sci. USA. 86:1372-1376.

5. Ylä-Herttuala, S., W. Palinski, M. E. Rosenfeld, S. Parthasarathy, T. E. Carew, S. Butler, J. L. Witztum, and D. Steinberg. 1989. Evidence for the presence of oxidatively modified low density lipoprotein in atherosclerotic lesions of rabbit and man. J. Clin. Invest. 84:1086-1095.

6. Boyd, H. C., A. M. Gown, G. Wolfbauer, and A. Chait. 1989. Direct evidence for a protein recognized by a monoclonal antibody against oxidatively modified LDL in atherosclerotic lesions from a Watanabe heritable hyperlipidemic rabbit. Am. J. Pathol. 135:815-825.

7. Steinbrecher, U. P. 1987. Oxidation of human low density lipoprotein results in derivatization of lysine residues of apolipoprotein B by lipid peroxide decomposition products. J. Biol. Chem. 262:3603-3608.

8. Hoff, H. F., J. O'Neil, G. M. Chislom, T. B. Cole, Q. Quehenberger, H. Esterbauer, and G. Jurgens. 1989. Modification of low density lipoprotein with 4-hydroxynenenal induces uptake by macrophages. Arteriosclerosis. 9:538-549.

9. Parthasarathy, S., L. G. Fong, D. Otero, and D. Steinberg. 1987. Recognition of solubilized apoproteins from delipidated, oxidized low density lipoprotein (LDL) by the acetyl-LDL receptor. Proc. Natl. Acad. Sci. USA. 84:537-540.

10. Sparrow, C. P., S. Parthasarathy, and D. Steinberg. 1989. A macrophage receptor that recognizes oxidized low density lipoprotein but not acetylated low density lipoprotein. J. Biol. Chem. 264:2599-2604.

11. Cathcart, M. K., A. K. McNally, D. W. Morel, and G. M. Chisolm. 1989. Superoxide anion participation in human monocyte-mediated oxidation of lowdensity lipoprotein and conversion of low-density lipoprotein to a cytotoxin. $J$. Immunol. 142:1963-1969.

12. Liao, F., J. A. Berliner, A. J. Mehrabian, M. Navab, L. L. Demer, A. J. Lusis, and A. M. Fogelman. 1991. Minimally modified low density lipoprotein is biologically active in vivo in mice. J. Clin. Invest. 87:2253-2257. (published erratum appears in J. Clin. Invest. 1991 88:721)

13. Cushing, S. D., J. A. Berliner, A. J. Valente, M. C. Territo, M. Navab, F. Parhami, R. Gerrity, C. J. Schwartz, and A. M. Fogelman. 1990. Minimally modified low density lipoprotein induces monocyte chemotactic protein 1 in human endothelial cells and smooth muscle cells. Proc. Natl. Acad. Sci. USA. 87:5134-5138.

14. The National Diet-Heart Study. 1968. American Heart Association Monograph No. 18, American Heart Association, New York.

15. Grundy, S. M., and M. A. Denke. 1990. Dietary influences on serum lipids and lipoproteins. J. Lipid. Res. 31:1149-1172.

16. Mattson, F. H., and S. M. Grundy. 1985. Comparison of effects of dietary saturated, monounsaturated, and polyunsaturated fatty acids on plasma lipids and lipoproteins in man. J. Lipid. Res. 26:194-202.

17. Berry, E. M., S. Eisenberg, D. Haratz, Y. Friedlander, Y. Norman, N. A. Kaufmann, and Y. Stein. 1991. Effects of diets rich in monounsaturated fatty acids on plasma lipoproteins-the Jerusalem Nutrition Study: high MUFAs vs high PUFAs. Am. J. Clin. Nutr. 53:899-907.

18. Reaven, P. D., S. Parthasarathy, B. J. Grasse, E. Miler, F. Almazan, F. H. Mattson, J. C. Khoo, D. Steinberg, and J. Witztum. 1991. Feasibility of using an oleate-rich diet to reduce the susceptibility of low density lipoprotein to oxidative modification in humans. Am. J. Clin. Nutr. 54:701-706.

19. Grundy, S. M. 1986. Comparison of monounsaturated fatty acids and carbohydrates for lowering plasma cholesterol. N. Engl. J. Med. 314:745-748.

20. Parthasarathy, S., J. Barnett, and L. Fong. 1990. High-density lipoprotein inhibits the oxidative modification of low-density lipoprotein. Biochim. Biophys. Acta. 1044:275-283.

21. Boothby, W. M., and R. B. Sandiford. 1921. Nomographic charts for the calculation of the metabolic rate by the gasometer method. Boston Med. Surg. J. 185:337.

22. Lowry, O. H., N. J. Rosebrough, A. L. Farr, and R. J. Randall. 1951 Protein measured with the folin phenol reagent. J. Biol. Chem. 193:265-275.

23. Salacinski, P. R. P., C. McLean, J. E. C. Sykes, V. V. Clement-Jones, and P. J. Lowry. 1982. Iodination of proteins, glycoproteins, and peptides using a solid-phase oxidizing agent. Anal. Biochem. 117:136-146.

24. Kaplan, L. A., J. A. Miller, and E. A. Stein. 1987. Simultaneous measurement of serum retinal, tocopherols, carotenes, and carotenoids by high performance liquid chromatography. J. Clin. Lab. Anal. 1:147-152.

25. Schudel, P., H. Mayer, and O. Islen. 1967. Tocopherols, II Chemistry. In Vitamins: Chemistry, Physiology, Pathology, Methods. Vol. 5. 2nd ed. W. H. Sebrell, Jr., R. S. Harris, editors. Academic Press, New York. 168-218.

26. Esterbauer, H., G. Striegl, H. Puhl, and M. Rotheneder. 1989. Continuous monitoring of in vitro oxidation of human low density lipoprotein. Free Radical Res. Commun. 6:67-75. 
27. el-Saadani, M., H. Esterbauer, M. el-Sayed, M. Goher, A. Y. Nasar, and G. Jurgens. 1989. A spectrophotometric assay for lipid peroxides in serum lipoproteins using a commercially available reagent. J. Lipid. Res. 30:627-630.

28. Folch, J., M. Lees, and G. H. Sloane Stanley. 1957. A simple method for the isolation and purification of total lipides from animal tissues. J. Biol. Chem. 226:497-509.

29. Gamble, W., M. Vaughan, H. S. Kruth, and J. Avigan. 1978. Procedure for determination of free and total cholesterol in micro- or naogram amounts suitable for studies with cultured cells. J. Lipid. Res. 19:1068-1070.

30. Bucolo, G., and H. David. 1973. Quantitative determination of serum triglycerides by the use of enzymes. Clin. Chem. 19:476-482.

31. Rouser, G., A. N. Siakotos, and S. Fleischer. 1966. Quantitative analysis of phospholipids by thin layer chromatography and phosphorus analysis of spots. Lipids. 1:85-86.

32. Stokes, J., III, W. B. Kannel, P. A. Wolf, L. A. Cupples, and R. B. D'Agostino. 1987. The relative importance of selected risk factors for various manifestations of cardiovascular disease among men and women from 35 to 64 years old: 30 years of follow-up on the Framingham Study. Circulation 75(Suppl.)(6, Pt. 2):V65-V73.
33. Castelli, W. B., R. J. Garrison, P. W. F. Wilson, R. D. Abbott, S. Kalousdian, and W. B. Kannel. 1986. The incidence of coronary heart disease and lipoprotein cholesterol levels: the Framingham Study. JAMA (J. Am. Med. Assoc.). 256:2835-2838.

34. Stamler, J., D. Wentworth, and J. D. Neation. Is relationship between serum cholesterol and risk of premature death from coronary heart disease continuous and graded? Findings in 356,222 primary screenees of the multiple Risk Factor Intervention Trial. JAMA (J. Am. Med. Assoc.). 256:2823-2828.

35. Report on the National Cholesterol Education Program Expert Panel on Detection, Evaluation, and Treatment of High Blood Cholesterol in Adults. 1988. Arch. Intern. Med. 148:36-69.

36. Gutteridge, J. M. C. 1982. Free-radical damage to lipids, amino acids, carbohydrates and nucleic acids determined by thiobarbituric acid reactivity. Int. J. Biochem. 14:649-653.

37. Halliwell, B., and S. Chirico. 1992. Lipid peroxidation: its mechanism, measurement and significance. Am. J. Clin. Nutr. In press.

38. Esterbauer, H., M. Retteneder, G. Striegle, G. Waeg, A. Ashy, W. Sattler, and G. Jurgens. 1989. Vitamin E and other lipophilic antioxidants protect LDL against oxidation. Fat Sci. Technol. 91:316-324. 